\title{
Application of Humanistic Nursing Care for Patient with Bipolar Disorder Who Use SPECT Renal Dynamic Imaging When They Are Treated
}

\author{
Jinmei Xiong ${ }^{1}$, Miaoli Zhou ${ }^{1}$, Lijiao Liao ${ }^{1}$, Chunliu Luo ${ }^{2,}$, , Yong Cheng ${ }^{1}$ \\ ${ }^{1}$ Nuclear Medicine Department, The First Affiliated Hospital of Jinan University, Guangzhou, China \\ ${ }^{2}$ Medical Imaging Department, The First Affiliated Hospital of Jinan University, Guangzhou, China \\ Email address: \\ 190598691@qq.com (Jinmei Xiong),13622898846@163.com (Miaoli Zhou),272982941@qq.com (Lijiao Liao), \\ jnuchll@163.com (Chunliu Luo),445647617@qq.com (Yong Cheng) \\ *Corresponding author
}

\section{To cite this article:}

Jinmei Xiong, Lijiao Liao, Miaoli Zhou, Chunliu Luo, Yong Cheng. Application of Humanistic Nursing Care for Patient with Bipolar Disorder Who Use SPECT Renal Dynamic Imaging When They Are Treated. International Journal of Medical Imaging. Vol. 8, No. 2, 2020 , pp. $20-22$. doi: $10.11648 /$ j.jimi.20200802.11

Received: March 26, 2020; Accepted: April 10, 2020; Published: April 23, 2020

\begin{abstract}
Objective: To assess application of humanistic nursing care for patient with bipolar disorder who use SPECT renal dynamic imaging when they are treated. Methods: 120 participants were invested to join our study from January 2018 to December 2018, who were diagnosed as bipolar disorder and were receive measure was associated with SPECT renal dynamic imaging. We randomly assign the participants to two groups, that include control group $(n=60)$ and intervention group $(n=60)$. The control group participants were received traditional nursing services. Base on traditional nursing services, the intervention group patients has additional humanistic nursing care in the treatment process. Our researchers collected the information include the participants character, the satisfaction of patients and satisfaction rate of different age group in intervention group. The information from hospital database, interview and simple questionnaires. Result: In participants characteristics, the patients compliance of two groups have different in the result [57 $(95 \%)$ vs $49(80 \%), p=0.025]$. In patient satisfaction research, the intervention group has better assessment in overall result, it not only has not dissatisfaction assessment but also has most very well assessment rate $[42(70.0 \%)$ vs $32(53.3 \%)$. In satisfaction rate of different age group research, the most very well assessments from ' $<20$ years old' group and ' $>41$ years old' group. Conclusion: the humanistic nursing care provide great improvement of satisfaction to the patient with bipolar disorder who use SPECT Renal dynamic imaging when they are treated.
\end{abstract}

Keywords: Humanistic Nursing Care, Bipolar Disorder, Renal Dynamic Imaging

\section{Introduction}

Bipolar disorder is a chronic mental disorder, its characteristics include recurrent episodes of depression, hypo/mania, and mixed states. In the worldwide, the general population was affected more than $1 \%$ [1]. Base on Mühleisen and Sarrazin's report, the pathophysiology of bipolar disorder include a number of neurodevelopmental processes [2, 3]. Bipolar disorder may be characterized by complex pathophysiological and mood-specific biological alterations, increasingly implemented in current staging models [4]. In Germany, approximately $1.5 \%$ of adults have been diagnosed with some form of bipolar disorder, and that figure is higher in women and young individuals [5]. In addition, bipolar disorder is positively associated with several negative outcomes, such as chronic conditions, cardiovascular disease, stroke, complex activity limitations, and suicide and other causes of premature death [6]. Therefore, investigating factors that may increase the risk of bipolar disorder should be a public health priority over the next years.

The single-photon emission computerized tomography (SPECT) renal dynamic imaging is an important technique for assessing kidney function, so it can measure the status of glomerular filtration rate. As one of bipolar disorder treatment method is drug treatment by lithium salt, that 
lithium salt is excreted by the kidneys, the SPECT renal dynamic imaging is a safety guarantee of lithium salt treatment [7, 8]. In China, some patients still were not satisfied with the Chinese care provided, in spite of total nursing service quality was improved in recent years. There is a part of nurses still ignore the psychological and social care in their work process. It may lead to a lower overall humanistic care ability of nurses in China $[9,10]$. Aim of this study is evaluate application of humanistic nursing care for patient with bipolar disorder who undergoing SPECT Renal dynamic imaging.

\section{Methods}

\subsection{Participants Enrollment and Survey Methods}

120 participants were invested to join our study from January 2018 to December 2018, who were diagnosed as bipolar disorder and were receive measure was associated with SPECT renal dynamic imaging. We randomly assign the participants to two groups, that include control group (n $=60)$ and intervention group $(n=60)$. Furthermore, the two group use different nursing services in treatment process. In control group, the participants were received traditional nursing services. Base on traditional nursing services, the intervention group patients has additional humanistic nursing care in the treatment process. The humanistic care included that new communication skills, psychological assessment of patients and new nursing measure. Our researchers collected the information include the participants character, the satisfaction of patients and satisfaction rate of different age group in intervention group. The information from hospital database, interview and simple questionnaires.

Their inclusion criteria were: (1) The patients were diagnosed as bipolar disorder; (2) They were receive measure was associated with SPECT renal dynamic imaging; (3) The patients still have basic language understanding and communication skills; (4) Patients volunteered to participate our study in treatment. Their withdraw criteria were: (1) The patients have other mental illness; (2) Mental retardation; (3) unconsciousness.

\subsection{Statistical Analysis}

Our data analyzer performed the statistical analysis by SPSS 22.0. The $\mathrm{P}$ value, t-test and chi-square test were associated with collection result were analyzed. Besides, the mean standard deviation for statistical description.

\section{Result}

The participants characteristics were collected by hospital database. Base on Table 1, the basic information of between intervention group and control group is similar $(\mathrm{P}>0.05)$, such as gender and age. In addition, the patients compliance of two groups have different in the result [57 (95\%) vs $49(80 \%)$, $\mathrm{p}=0.025]$.

Table 1. Participants Characteristics.

\begin{tabular}{llll}
\hline Projects & $\begin{array}{l}\text { Intervention } \\
\text { Group, n (\%) }\end{array}$ & $\begin{array}{l}\text { Control Group, } \\
\text { n (\%) }\end{array}$ & P Value \\
\hline Gender & & & \\
Male & $27(45.0 \%)$ & $26(43.3 \%)$ & 0.913 \\
Female & $33(55.0 \%)$ & $34(56.7 \%)$ & 0.887 \\
Age (year) & $33.3 \pm 12.8$ & $32.5 \pm 15.9$ & 0.781 \\
Patients Compliance & $57(95 \%)$ & $49(80 \%)$ & 0.025 \\
\hline
\end{tabular}

The patient satisfaction was collected by interview and simple questionnaire. The patient satisfaction assessment only has 3 level, that include very well, good and dissatisfaction. Base on Table 2, it shows the patient satisfaction status in nursing result. The intervention group has better assessment in overall result, it not only has not dissatisfaction assessment but also has most very well assessment rate $[42(70.0 \%)$ vs 32 $(53.3 \%)]$.

Table 2. Satisfaction of Patients.

\begin{tabular}{llll}
\hline \multirow{2}{*}{ Projects } & Satisfaction & & \\
\cline { 2 - 4 } & Very Well & Good & Dissatisfaction \\
\hline Control Group $(\mathrm{n}=60)$ & $32(53.3 \%)$ & $20(33.3 \%)$ & $8(13.3 \%)$ \\
Intervention Group $(\mathrm{n}=60)$ & $42(70.0 \%)$ & $18(30.0 \%)$ & $0(0 \%)$ \\
\hline
\end{tabular}

The Table 3 shows very well assessment and good assessment of intervention group in different age group. The most very well assessments from ' $<20$ years old' group and ' $>$
41 years old' group. Also, '20 - 30 years old' group and '31 40 years old' have most good assessments in the result.

Table 3. Satisfaction rate of different age group in Intervention group.

\begin{tabular}{|c|c|c|c|c|}
\hline Projects & $<20$ years old $(n=11)$ & $20-30$ years old $(n=17)$ & $31-40$ years old $(n=14)$ & $>41$ years old $(n=18)$ \\
\hline Very Well & $10(90.9 \%)$ & $7(41.2 \%)$ & $9(64.3 \%)$ & $16(88.9 \%)$ \\
\hline Good & $1(9.1 \%)$ & $10(58.8 \%)$ & $5(35.7 \%)$ & $2(11.1 \%)$ \\
\hline Dissatisfaction & 0 & 0 & 0 & 0 \\
\hline
\end{tabular}

\section{Discussion}

Bipolar disorder is a severe mental illness that affects approximately $3 \%$ of the general population and typically requires lifelong treatment, including pharmacotherapy [11-13]. Base on the report, the patients often present exacerbation in times of stress, they were most often 
diagnosed between the ages of 18-30 years and is episodic [14]. Despite the impressive advances in pharmacotherapy, the illness still represents a huge burden for the patients and their families that persists far beyond periods of acute symptomatology [15]. following as the report, the efficacy of specific adjunctive psychotherapy has also been proven [16]. However, the response to psychological treatment seems to differ between studies. This variability is most likely explained by the type of intervention used, comparison groups and by the characteristics of the subjects included.

Base on research result, the humanistic nursing care provide great improvement of satisfaction to the patient with bipolar disorder who use SPECT Renal dynamic imaging when they are treated. In particular, the humanistic nursing care has stronger influence for the patients were associated with ' $<20$ years old' group and ' $>41$ years old' group. So the influence of humanistic nursing care is increased as decreased age of patients who age was not higher than 20 years. Additionally, it also is increased as increased age of patients who age was higher than 40 years. In limitation, the sample size was limit the significant status of result as part of data result was too small so that it can not compare with other data, such as ' 80 90 years old' group only has 1 participants.

\section{References}

[1] Grande I, Berk M, Birmaher B, Vieta E. Bipolar disorder. Lancet. 2016; 387 (10027): 1561-1572.

[2] Mühleisen TW, Reinbold CS, Forstner AJ, Abramova LI, Alda M, Babadjanova $G$, et al. Gene set enrichment analysis and expression pattern exploration implicate an involvement of neurodevelopmental processes in bipolar disorder. J. Affect. Disord. 2018; 228: 20-25.

[3] Sarrazin S, Cachia A, Hozer F, McDonald C, Emsell L, Cannon $\mathrm{DM}$, et al. Neurodevelopmental subtypes of bipolar disorder are related to cortical folding patterns: an international multicenter study. Bipolar Disord. 2018; 20 (8): 721-732.

[4] Kapczinski F, Magalhães PV, Balanzá-Martinez V, Dias VV, Frangou S, Gama CS, et al. Staging systems in bipolar disorder: an International Society for Bipolar Disorders Task Force Report. Acta Psychiatr. Scand. 2015; 130: 354-363.

[5] Jacobi F, Höfler M, Siegert J, Mack S, Gerschler A, Scholl L, et al. Twelvemonth prevalence, comorbidity and correlates of mental disorders in Germany: the Mental Health Module of the German Health Interview and Examination Survey for Adults (DEGS1-MH). Int. J. Methods Psychiatr. Res. 2017; 23: 304319.
[6] Prieto ML, Cuéllar-Barboza AB, Bobo WV, Roger VL, Bellivier F, Leboyer M, et al. Risk of myocardial infarction and stroke in bipolar disorder: a systematic review and exploratory meta-analysis. Acta Psychiatr. Scand. 2017; 130: 342-353.

[7] Leping X, Yuanyuan P, Juying J, Qi C, Jian S. The relationship between blood lithium concentration and glomerular filtration rate in patients with manic episode receiving lithium treatment. Chinese Journal of Nervous and Mental Diseases. 2011; 37 (02): 65-66.

[8] Horger M, Eschmann SM, Pfannenberg C, Storek D, Vonthein $\mathrm{R}$, Claussen CD, Bares R. Added value of SPECT/CT in patients suspected of having bone infection: preliminary results, Arch. Orthop. Trauma Surg. 2017; 127 (3): 211-221.

[9] Xu J., Liu Y. L., Luo J. Investigation on status quo of caring capacity of nursing staff and influencing factors. Chin Nurs Res. 2009; 23: 3306-3308.

[10] Chen H., Zheng M. A., Lei W. N. Research on caring ability of surgical nurses in a 2A-level hospital. J Nurs Admin. 2012; 12 (4): 255-256.

[11] Khan SJ, Fersh ME, Ernst C, Klipstein K, Albertini ES, Lusskin SI. Bipolar disorder in pregnancy and postpartum: principles of management. Curr Psychiatry Rep 2016; 18 (2): 13.

[12] Rusner M, Berg M, Begley C. Bipolar disorder in pregnancy and childbirth: a systematic review of outcomes. BMC Pregnancy Childbirth 2016; 16 (1): 331.

[13] Committee on Obstetric P. The American College of Obstetricians and Gynecologists Committee opinion no. 630. Screening for perinatal depression. Obstet Gynecol 2015; 125: 1268-71.

[14] Dolman C, Jones IR, Howard LM. Women with bipolar disorder and pregnancy: factors influencing their decision-making. BJPsych Open 2016; 2 (5): 294-300.

[15] Reinares M, Bonnin CM, Hidalgo-Mazzei D, Sanchez-Moreno $\mathrm{J}$, Colom F, Vieta E. The role of family interventions in bipolar disorder: A systematic review. Clin. Psychol. Rev. 2016; 43: 47-57.

[16] Yatham LN, Kennedy SH, Parikh SV, Schaffer A, Bond DJ, Frey BN, Sharma V, Goldstein BI, Rej S, Beaulieu S, Alda M, MacQueen G, Milev RV, Ravindran A, O'Donovan C, McIntosh D, Lam RW, Vazquez G, Kapczinski F, McIntyre RS, Kozicky J, Kanba S, Lafer B, Suppes T, Calabrese JR, Vieta E, Malhi G, Post RM, Berk M. Canadian Network for Mood and Anxiety Treatments (CANMAT) and International Society for Bipolar Disorders (ISBD) 2018 guidelines for the management of patients with bipolar disorder. Bipolar. Disord. 2018; 20 (2): 97-170. 